NASA/TM-2004-213300

Review of Computational Stirling Analysis Methods

Rodger W. Dyson

Glenn Research Center, Cleveland, Ohio

Scott D. Wilson

Sest, Inc., Middleburg Heights, Ohio

Roy C. Tew

Glenn Research Center, Cleveland, Ohio 
Since its founding, NASA has been dedicated to the advancement of aeronautics and space science. The NASA Scientific and Technical Information (STI) Program Office plays a key part in helping NASA maintain this important role.

The NASA STI Program Office is operated by Langley Research Center, the Lead Center for NASA's scientific and technical information. The NASA STI Program Office provides access to the NASA STI Database, the largest collection of aeronautical and space science STI in the world. The Program Office is also NASA's institutional mechanism for disseminating the results of its research and development activities. These results are published by NASA in the NASA STI Report Series, which includes the following report types:

- $\quad$ TECHNICAL PUBLICATION. Reports of completed research or a major significant phase of research that present the results of NASA programs and include extensive data or theoretical analysis. Includes compilations of significant scientific and technical data and information deemed to be of continuing reference value. NASA's counterpart of peerreviewed formal professional papers but has less stringent limitations on manuscript length and extent of graphic presentations.

- TECHNICAL MEMORANDUM. Scientific and technical findings that are preliminary or of specialized interest, e.g., quick release reports, working papers, and bibliographies that contain minimal annotation. Does not contain extensive analysis.

- CONTRACTOR REPORT. Scientific and technical findings by NASA-sponsored contractors and grantees.
- CONFERENCE PUBLICATION. Collected papers from scientific and technical conferences, symposia, seminars, or other meetings sponsored or cosponsored by NASA.

- SPECIAL PUBLICATION. Scientific, technical, or historical information from NASA programs, projects, and missions, often concerned with subjects having substantial public interest.

- TECHNICAL TRANSLATION. Englishlanguage translations of foreign scientific and technical material pertinent to NASA's mission.

Specialized services that complement the STI Program Office's diverse offerings include creating custom thesauri, building customized databases, organizing and publishing research results ... even providing videos.

For more information about the NASA STI Program Office, see the following:

- Access the NASA STI Program Home Page at http://www.sti.nasa.gov

- E-mail your question via the Internet to help@sti.nasa.gov

- Fax your question to the NASA Access Help Desk at 301-621-0134

- Telephone the NASA Access Help Desk at 301-621-0390

- Write to:

NASA Access Help Desk

NASA Center for AeroSpace Information 7121 Standard Drive

Hanover, MD 21076 
NASA/TM-2004-213300

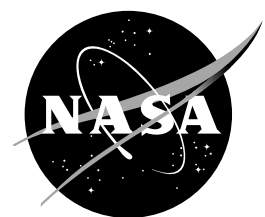

\section{Review of Computational Stirling Analysis Methods}

Rodger W. Dyson

Glenn Research Center, Cleveland, Ohio

Scott D. Wilson

Sest, Inc., Middleburg Heights, Ohio

Roy C. Tew

Glenn Research Center, Cleveland, Ohio

Prepared for the

Second International Energy Conversion Engineering Conference sponsored by the American Institute of Aeronautics and Astronautics Providence, Rhode Island, August 16-19, 2004

National Aeronautics and

Space Administration

Glenn Research Center 


\section{Acknowledgments}

This work was performed for NASA Headquarters, Office of Space Science (Code S), under Project Prometheus, the Nuclear Systems Program.

Trade names or manufacturers' names are used in this report for identification only. This usage does not constitute an official endorsement, either expressed or implied, by the National Aeronautics and Space Administration.

Available from

NASA Center for Aerospace Information 7121 Standard Drive

Hanover, MD 21076
National Technical Information Service 5285 Port Royal Road Springfield, VA 22100 


\title{
Review of Computational Stirling Analysis Methods
}

\author{
Rodger W. Dyson \\ National Aeronautics and Space Administration \\ Glenn Research Center \\ Cleveland, Ohio 44135 \\ Scott d. Wilson \\ Sest, Inc. \\ Middleburg Heights, Ohio 44130 \\ Roy C. Tew \\ National Aeronautics and Space Administration \\ Glenn Research Center \\ Cleveland, Ohio 44135
}

\begin{abstract}
Nuclear thermal to electric power conversion carries the promise of longer duration missions and higher scientific data transmission rates back to Earth for a range of missions, including both Mars rovers and deep space missions. A free-piston Stirling convertor is a candidate technology that is considered an efficient and reliable power conversion device for such purposes. While already very efficient, it is believed that better Stirling engines can be developed if the losses inherent in current designs could be better understood. However, they are difficult to instrument and so efforts are underway to simulate a complete Stirling engine numerically. This has only recently been attempted and a review of the methods leading up to and including such computational analysis is presented. And finally it is proposed that the quality and depth of Stirling loss understanding may be improved by utilizing the higher fidelity and efficiency of recently developed numerical methods. One such method, the Ultra HI-FI technique is presented in detail.
\end{abstract}

\section{Introduction}

$\mathrm{P}$ OWER conversion with free-piston Stirling engines ${ }^{1,2}$ has the potential to deliver high efficiency, low mass solutions for longer and more varied space missions. ${ }^{3,4}$ NASA's goal of achieving $35 \%$ system efficiency (approximately $45 \%$ convertor efficiency) will require increasing the percentage of Carnot efficiency that is achievable to $55 \%$. In addition to using advanced high-temperature materials to increase the Carnot temperature ratio, it is anticipated that advanced computational fluid dynamics (CFD) will help to identify the following losses ${ }^{6,7,8}$ (also shown in figure I):

1. Inefficient heat exchange and pressure loss in the regenerator, heater and cooler,

2. Gas spring and working space loss due to hysterisis and turbulence,

3. Appendix gap losses due to pumping and shuttle effects,

4. Mixing gas losses from nonuniform temperature and flow distributions perpendicular to primary engine flow axis,

5. Conduction losses from the hot to cold regions 
6. Losses due to combined radiation, conduction and convection in hollow spaces

7. And in general, inaccurate loss representations due to use of 1-D flow design codes to account for flow and heat transfer through area changes (between components) where phenomena such as flow separation and jetting from tube into regenerator may occur.

In addition, the following artificial numerical losses must be considered when computational simulations are performed (also shown in figure 1):

1. Moving/deforming mesh losses from repeated low order flow field interpolations,

2. Transient/Unsteady heat transfer and flow loss from inconsistent and inaccurate time discretization,

3. Flow loss from low order approaches resulting in effectively adding artificial dissipation terms along sliding interfaces, at structured/unstructured grid interfaces, and within interior.

Minimizing those artificial losses is best accomplished through higher order approaches. ${ }^{9}$ While this approach is common in aeroacoustics, computational electromagnetics, and exterior flow problems, high order techniques have not yet been applied to simulating a Stirling device. Moreover, the following difficulties are often encountered when using high-order approaches:

1. Generation of high-order, smooth, body-fitted grids around complex configurations can be difficult. ${ }^{10}$

2. High-order formulations can lack nonlinear robustness. ${ }^{10}$

3. The general usefulness of high-order methods is limited by first order accurate shock capturing. ${ }^{11}$

Fortunately, with the exception of the possibly random geometry in the regenerator, the free-piston design is essentially smooth and admits curvilinear structured grids. The issue of nonlinear robustness is an open issue, but a proposed approach is detailed later. And finally, the working gas is subsonic and shockless throughout the entire region. ${ }^{12}$ For these reasons, a high-order approach should be investigated for "whole engine" Stirling analysis.

This paper will highlight the past and present Stirling analysis techniques and discuss their relative merits. 


\section{Schematic with Springs and Dampers}

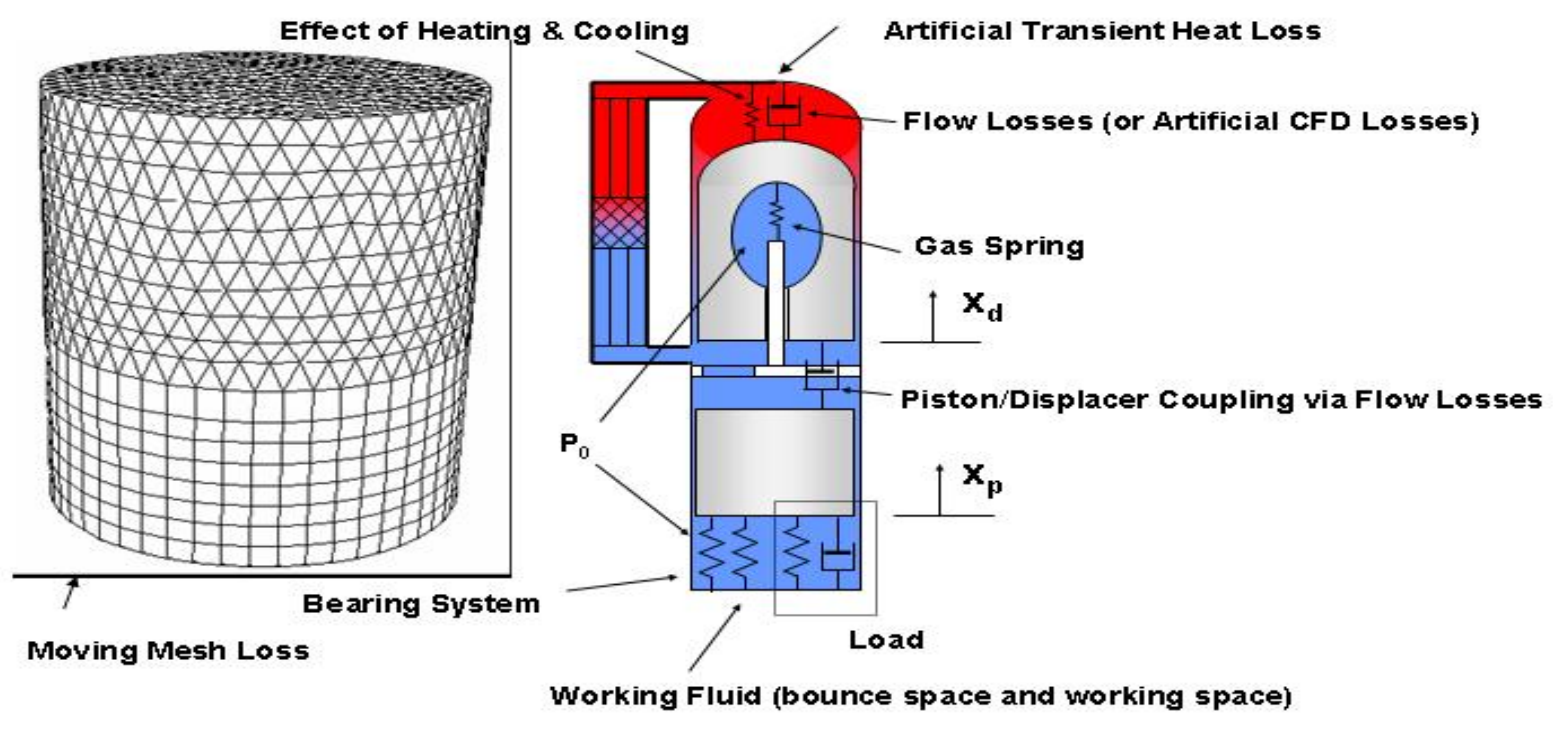

Figure 1. Schematic of Actual and Artificial Numerical Losses in a Free-Piston Convertor

\section{Description of the Problem}

The dual opposed configuration shown in figure $2^{13,17,18}$ is being developed for multimission use (i.e., for use in atmospheres and space), including providing electric power for potential missions such as unmanned Mars rovers and deep space missions. ${ }^{19}$

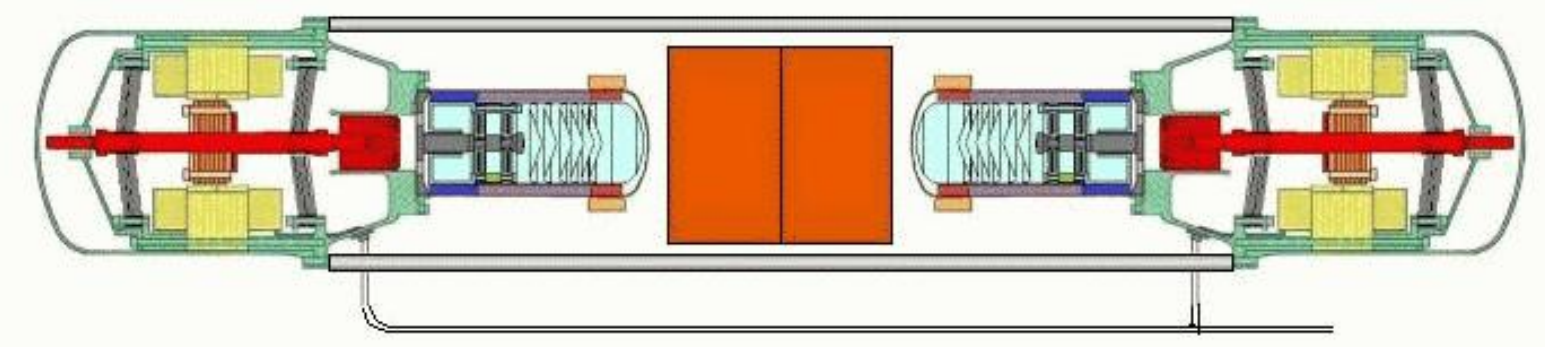

Figure 2. Dual Opposed Stirling Convertors Reduce Vibration (Schreiber)

An example of the desired full Stirling engine simulation is shown in Fig. $3 .{ }^{16}$ The pseudo design is presented to avoid export control issues. It is anticipated that full 3D simulations will provide a level of geometric and flow detail necessary for further design improvements. For example, hardware experiments 
have shown that large performance gains can be made by varying manifolds and heat exchanger designs to improve flow distributions in the heat exchangers. ${ }^{13,14,15}$

The kinds of flow and geometry that occur in a Stirling engine for which a modeling technique must address are as follows: ${ }^{8,7}$

1. Oscillating flow which changes the effective conduction, flow friction coefficients and heat diffusion. ${ }^{20}$

2. Low mach number flow (no shocks),

3. Compressible flow due to enclosed varying volumes and heat transfer effects,

4. Laminar, Transitional, and Turbulent flow with Reynolds numbers from 100 to 10000 (based on various length scales pertinent to the flow region),

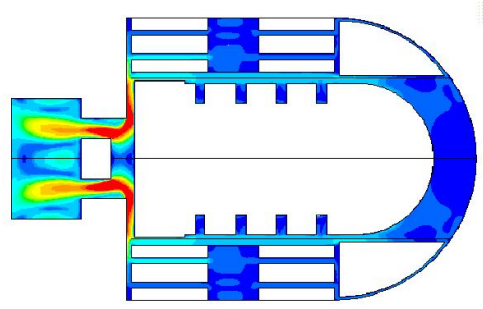

Figure 3. Example Transient Simulation of Pseudo Stirling Convertor-Colored by Velocity Magnitude

5. Conjugate heat transfer, thermal dispersion and local thermal nonequilibrium in the porous media regenerator,

6. Micron to Millimeter scale geometry ${ }^{21}$

7. Sliding Interfaces in the appendix gap

8. Deforming Flow Regions Due to Compression and Expansion

\section{Stirling Cycle Analysis Approaches}

The techniques of analysis for Stirling engines can be categorized with Martini's ${ }^{22,23}$ nomenclature as follows:

\section{A. Zeroth Order Analysis}

William Beale observed ${ }^{24}$ that most modern engines operate under similar conditions of the parametric ratios: dead volume ratio, temperature ratio, swept volume ratio, displacer-piston phase angle advance. Thus correlating the experimental data available on various engines, he found that one could represent the engine performance as:

$$
P_{0}=0.015 p_{\text {mean }} V_{\text {sw }} f
$$

\section{B. First Order Analysis}

The first analysis of Stirling engines was done in 1871 by Gustav Schmidt in which he obtained closed-form solutions for the special case of sinusoidal volume variations and isothermal hot and cold spaces. ${ }^{25}$ In Fig. B (a), the model equations from the isothermal assumption shown in Fig. 4 is shown. These can be integrated with a computer but a closed form solution is available in which sinusoidal motion is assumed.

The relative volume changes can be calculated using the phasor diagram and schematic in Figs. 5 (b and c). This analysis is loss-free and a correction factor is normally applied in practical designs to account for the losses. 

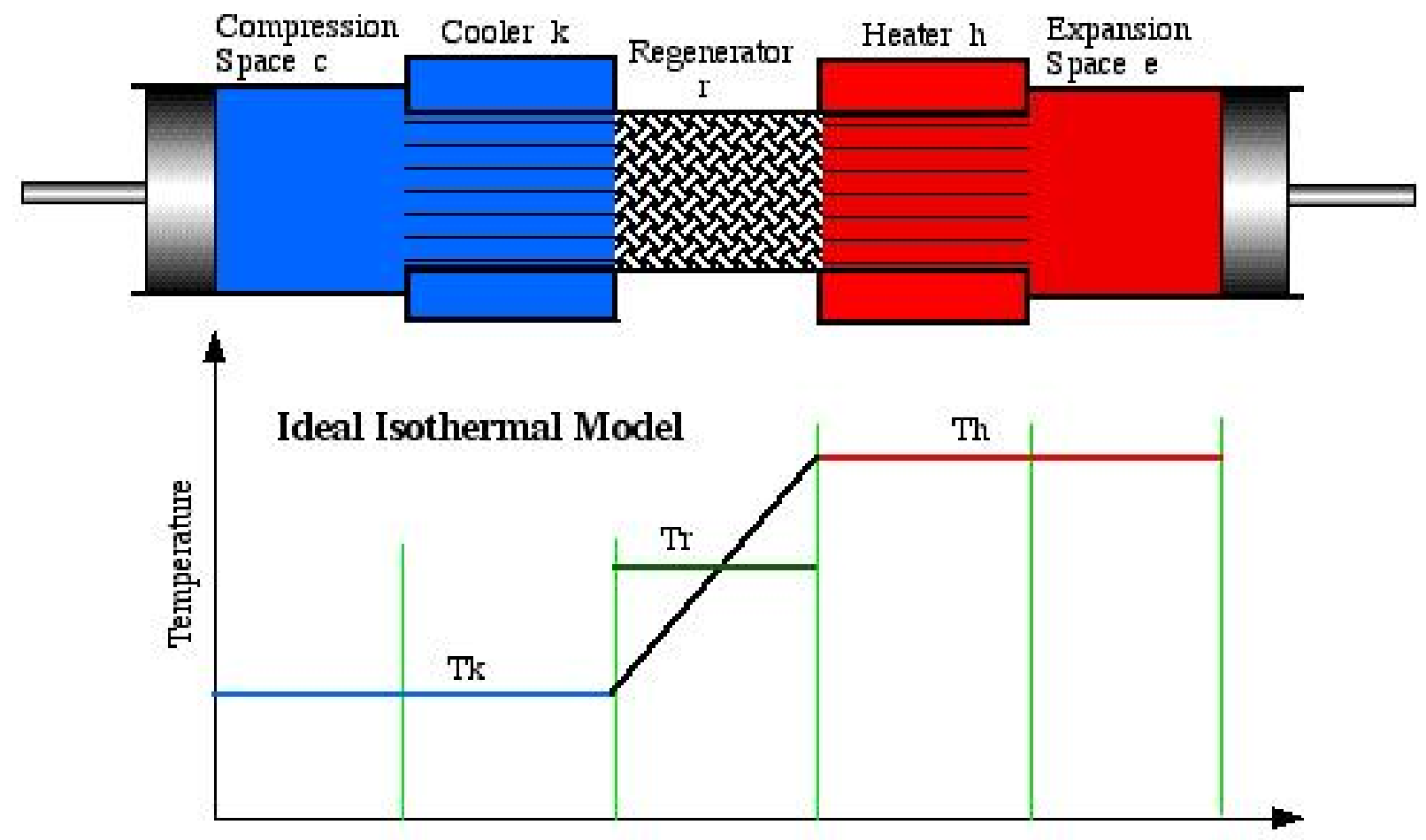

Figure 4. Ideal Isothermal Model (Urieli)

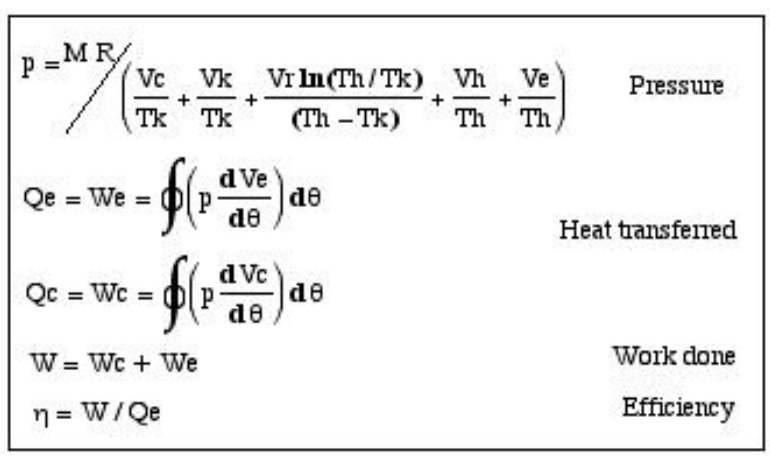

(a) Ideal Isothermal model set of equations

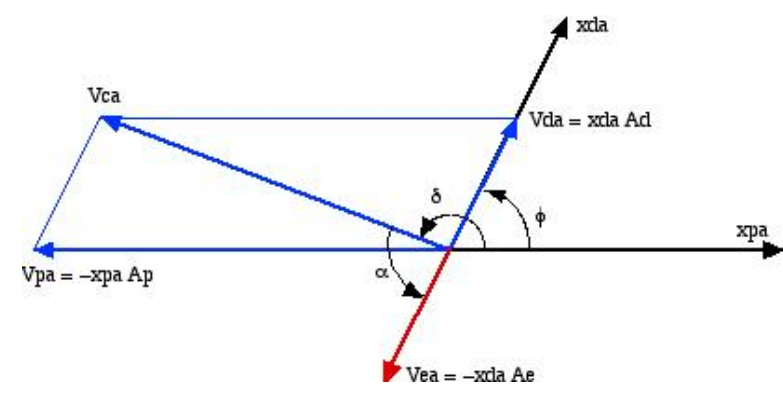

(b) Volume Vector Diagram

Figure 5. Closed Form Solution Process (Urieli) 


\section{Second Order Analysis}

This level of analysis may be based on an adiabatic analysis that subtracts losses caused by heat transfer and flow power losses. It relies on a modified Schmidt analysis (Schmidt analysis normally implies isothermal hot and cold spaces) and requires nonlinear time integration of the model equations. It assumes adiabatic expansion and compression regions as shown in Fig. 6(a).

\section{Heat Transfer Losses}

Heat transfer loss occurs throughout the system but notably in the appendix gap region (space between displacer and heat exchangers) through the following processes: ${ }^{24}$

- Shuttle heat transfer in which a conduction loss down the displacer or piston and associated cylinder is enhanced by one wall's oscillatory motion ${ }^{27}$

- Gas enthalpy transfer (pumping) which is the net enthalpy transport down the gap by virtue of the working gas motion, pressure and temperature.

- Hysteresis heat transfer which is the net heat transfer from the gas to the cylinder due to temperature gradients set up by the pressure variations in the expansion space.

In addition, conduction losses through the wall and displacer must be accounted for.

\section{Flow Power Losses}

Flow power loss occurs mostly in the regenerator region due to pressure drop across the matrix (which may be enhanced by non-uniform flow). The viscosity of the working gas and gas spring hysteresis losses must also be accounted for.

\section{Berchowitz Dynamic and Thermondynamic Closed Form}

A closed form expression (Fig. 7) which included masses for dynamic as well as thermodynamic analysis was derived by Berchowitz. ${ }^{26}$

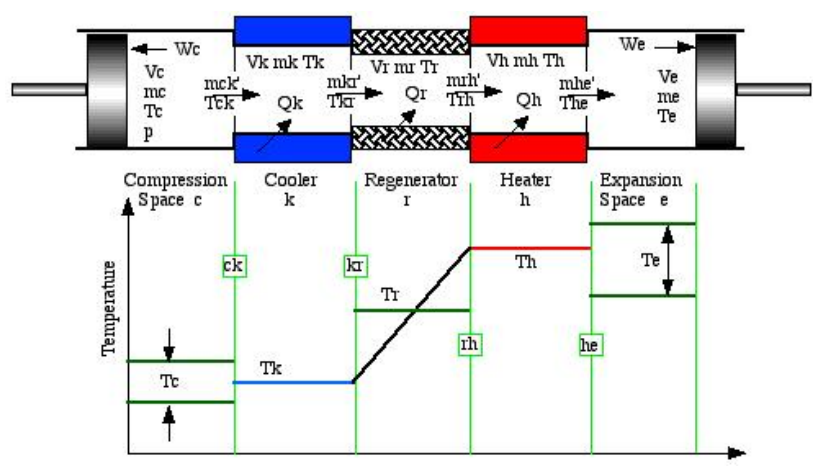

(a) Ideal Adiabatic Model

\begin{tabular}{|c|c|}
\hline $\mathbf{d p}=\frac{-\gamma \mathrm{p}(\mathbf{d V c} / \mathrm{Tck}+\mathbf{d V e} / \mathrm{The})}{[\mathrm{Vc} / \mathrm{Tck}+\gamma(\mathrm{Vk} / \mathrm{Tk}+\mathrm{Vr} / \mathrm{Tr}+\mathrm{Vh} / \mathrm{Th})+\mathrm{Ve} / \mathrm{The}]}$ & Pressure \\
\hline $\begin{array}{l}\mathrm{mc}=\mathrm{p} \mathrm{Vc} /(\mathrm{R} T \mathrm{Tc}) \\
\mathrm{mk}=\mathrm{p} \mathrm{Vk} /(\mathrm{R} \mathrm{Tk}) \\
\mathrm{mr}=\mathrm{p} \mathrm{Vr} /(\mathrm{RT}) \\
\mathrm{ml}=\mathrm{p} \mathrm{Vh} /(\mathrm{RTh}) \\
\mathrm{me}=\mathrm{p} \mathrm{Ve} /(\mathrm{R} \mathrm{Te})\end{array}$ & Masses \\
\hline $\begin{array}{l}\mathbf{d m c}=(\mathrm{p} \mathbf{d V c}+\mathrm{Vc} \mathbf{d p} / \gamma) /(\mathrm{R} \text { Tck }) \\
\mathbf{d m e}=(\mathrm{p} \mathbf{d V e}+\mathrm{Ve} \mathbf{d p} / \gamma) /(\mathrm{R} \text { The }) \\
\mathbf{d m k}=\operatorname{mk} \mathbf{d p} / \mathrm{p} \\
\mathbf{d m r}=\operatorname{mr} \mathbf{d p} / \mathrm{p} \\
\mathbf{d m h}=\operatorname{mh} \mathbf{d p} / \mathrm{p}\end{array}$ & $\begin{array}{l}\text { Mass } \\
\text { Accumulations }\end{array}$ \\
\hline $\begin{array}{l}\mathrm{mck}^{\prime}=-\mathbf{d m c} \\
\mathrm{mka}^{\prime}=\mathrm{mck}^{\prime}-\mathbf{d m k} \\
\mathrm{mhe}^{\prime}=\mathbf{d m e} \\
\mathrm{mrh}=\mathrm{mhe} \\
\end{array}$ & Mass Flow \\
\hline $\begin{array}{l}\text { if mck }>0 \text { then } T c k=T c \text { else } T c k=T k \\
\text { if mhe' }>0 \text { then The }=T \text { The else } T \text { The }=T e\end{array}$ & $\begin{array}{l}\text { Conditional } \\
\text { Temperatures }\end{array}$ \\
\hline $\begin{array}{l}\mathbf{d T c}=\operatorname{Tc}(\mathbf{d p} / \mathrm{p}+\mathbf{d V c} / \mathrm{Vc}-\mathbf{d m c} / \mathrm{mc}) \\
\mathbf{d T e}=\mathrm{Te}(\mathbf{d p} / \mathrm{p}+\mathbf{d V e} / \mathrm{Ve}-\mathbf{d m e} / \mathrm{me})\end{array}$ & Temperatures \\
\hline 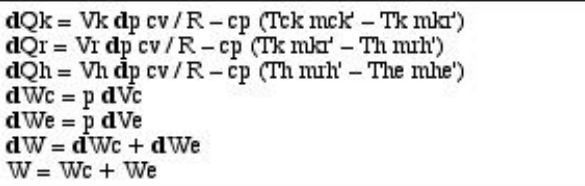 & Energy \\
\hline
\end{tabular}

(b) Ideal Adiabatic Model Equations

Figure 6. Adiabatic Solution Process (Urieli) 


\section{Third Order Analysis}

Third order analysis uses control volumes or nodes to directly solve one-dimensional governing equations. Some of the first analysis at this level of fidelity was by Finkelstein, ${ }^{28}$ Urieli, ${ }^{29}$ and Berchowitz. ${ }^{30}$

The codes by David Gedeon referred to as GLIMPS ${ }^{31,32}$ and Sage $^{33,34,35}$ are onedimensional and solve the governing equations implicitly in space and time. The grid includes all time because a periodic solution is assumed/forced. Therefore, it is not possible to model transient startup behavior.

The linearized harmonic analysis code referred to as $\mathrm{HFAST}^{36}$ solved a steady-state periodic problem in the frequency domain. Again, transient behavior is not modeled.

The code by Martini engineering ${ }^{37}$ was never validated but claimed transient modeling capability. It is not clear the governing equations are being solved since it appears many simplifications based on experimental correlations are used.

Another unvalidated but interesting code by Renfroe $^{38}$ attempted a one-dimensional analysis using explicit Runge-Kutta time stepping and a

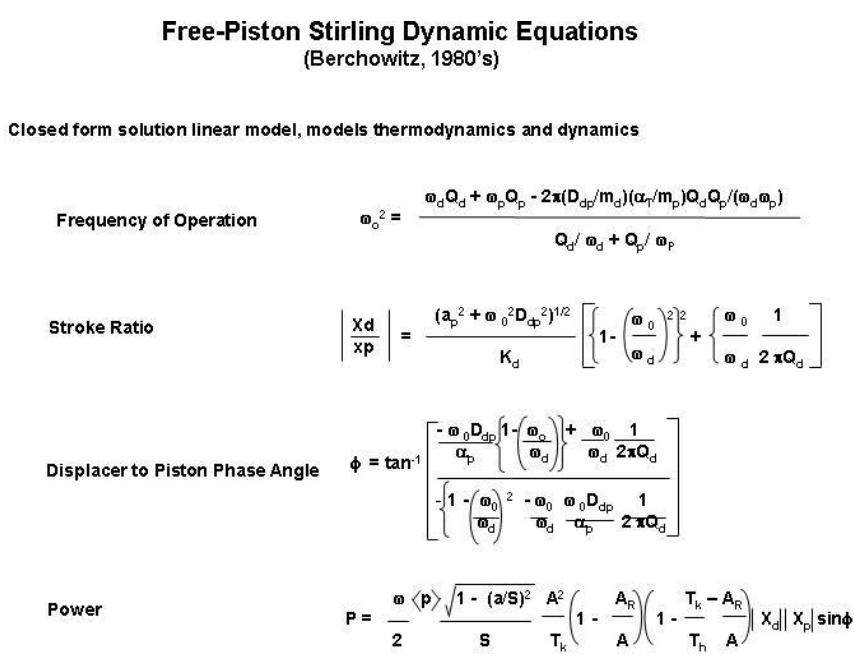

Figure 7. Closed Form Adiabatic Solution (Schreiber) Newton solver to solve the nonlinear equations.

Finally, the Stirling dynamic model (SDM) ${ }^{39}$ uses a one-dimensional analogy of an entire Stirling convertor by linking together representative elements within the Simplorer(TM) commercial software package by Ansoft Corp. This tool enables approximate whole convertor dynamic analysis. Recent work attempts to incorporate thermodynamics via David Gedeon's Sage code described earlier.

\section{E. Fourth Order (Multi-Dimensional) Analysis}

At this level of analysis, relatively little has been completed because the third order analysis is faster and for the most part has been an adequate engineering tool. However, to improve efficiency further (to understand and reduce losses) it will likely require a better understanding of the actual flow features and heat transfer throughout the engine.

\section{Modified Computer Aided Simulation of Turbulence (CAST)}

The modified CAST code $^{40}$ is based upon the Semi-Implicit Method for Pressure-Linked Equations SIMPLE $^{41}$ method but is restricted to two dimensions. ${ }^{42}$ It was modified to include oscillatory boundary conditions and conjugate heat transfer. It has been used to model Stirling components but has not been extended to a whole engine simulation tool.

A pressure-splitting technique was added ${ }^{43}$ to reduce the computational requirements. It was based on separating the thermodynamic and hydrodynamic pressures so that these widely varying scales could be solved with less round-off error and better efficiency. 


\section{2. $C F D-A C E$}

This commercial code has been used to model a two-dimensional representative Stirling engine. ${ }^{44,45}$ It is also based upon the SIMPLE technique. The regenerator is not currently modeled correctly since thermal equilibrium is assumed between the gas and solid. The code does not currently support sliding interfaces on parallel computers which is critical for modeling the appendix gap region.

This finite volume code can utilize both structured and unstructured grids.

\section{Fluent}

This commercial code is also based upon the SIMPLE method (and PISO method for high speed flows). It currently has similar regenerator modeling limitations in that it is designed for non-oscillating flows. It does however have a sliding interface that could be used for appendix gap modeling on parallel computers. It is being used by several commercial manufacturers for this purpose (references are proprietary). It is also finite volume based and can utilize both structured and unstructured grids.

\section{STAR-CD}

The Simulation of Turbulent Flow in Arbitrary Regions (STAR) ${ }^{46}$ code also uses SIMPLE and PISO methods. Its companion product (STAR-HPC) is the parallel computer version. It also has sliding interfaces and deforming mesh capability. It has been used in the related field of internal combustion engine piston modeling, and some Stirling engines have been modeled with it. ${ }^{47}$

\section{5. $C F X$}

This code also used SIMPLE and PISO methods on unstructured grids. It also has sliding interfaces implemented, but no stirling engine modeling with this software has been publicly published. ${ }^{48}$

\section{Others}

While there are other in-house codes, they are usually limited to modeling only specific regions of the Stirling engine such as the regenerator, or the displacer.

\section{Whole Engine Modeling}

The use of two-dimensional CFD models can significantly extend the capabilities, compared to third-order analysis, for the more detailed analysis of the complex heat transfer and gas dynamical processes which occur in the internal gas circuit. ${ }^{52} \mathrm{~A}$ standard $\kappa-\epsilon$ turbulence model has been used for such two-dimensional simulations, but the flow is constantly transitioning from laminar to turbulent and back. A better numerical model would be large eddy simulation due to the transient nature of the flow. More recently, full 3-D calculations have been performed with a commercial code. ${ }^{53}$ The temperature results are similar to the second order method results. ${ }^{54}$ The multidimensionally computed power, however, was about half of the second order prediction. Moreover, along the axis of the compression space it was found the change of the temperature of the working gas was quite different from harmonic in time. Third order modeling efforts can resolve higher harmonics of periodic time functions and therefore if enough grid points are available in time they can achieve similar results. However, turbulence is inherently a-periodic and it is not clear if third order modeling efforts which assume periodic solutions can fully capture this. 


\section{Regenerator Modeling}

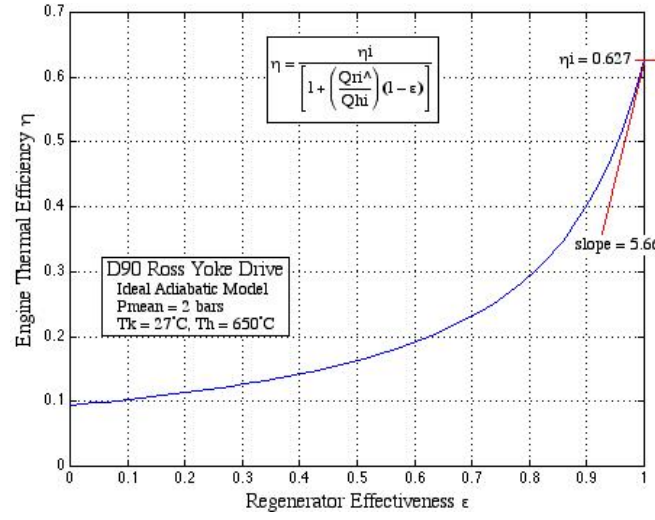

Figure 8. Importance of Properly Modeling the Regenerator for System Studies (Urieli)

A very important specific area of modeling difficulty is the regenerator. As shown in Fig. 8, since the regenerator (depending upon one's definition of effective) has roughly 3 to 40 times more effective heat transfer than the heater, ${ }^{55}$ any inefficiency of the regenerator represents a significant loss for the entire Stirling engine. Hence, any numerical losses in this region will disproportionately influence the entire Stirling simulation. A new low loss numerical method will be proposed later to address this.

\section{A. Manifest}

The code referred to as Manifest ${ }^{21}$ solved the porous medium model equations shown below:

$$
\begin{aligned}
& \frac{\partial M}{\partial \tau}+\frac{J}{\beta} \frac{\partial}{\partial y_{k}}\left(\frac{G^{k}}{J}\right)=0 \\
& \frac{\partial G^{n}}{\partial \tau}+\left(J \frac{\partial}{\partial y_{k}}\left(\frac{G^{k}}{J} u_{j}-\frac{\beta}{J} \tau_{e i j} \frac{\partial y_{k}}{\partial x_{i}}\right)+\beta J \frac{\partial}{\partial y_{k}}\left(\frac{P}{J} \frac{\partial y_{k}}{\partial x_{j}}\right)+\beta \psi_{j k} u_{k}\right) \frac{\partial y_{n}}{\partial x_{j}}=0 \\
& \frac{\partial E}{\partial \tau}+\frac{J}{\beta} \frac{\partial}{\partial y_{k}}\left(\frac{E}{J} \beta u^{k}+\frac{1}{J}(P \beta V)^{k}-\frac{1}{J}\left(\tau_{e}-\beta V\right)^{k}+\frac{\beta}{J} q_{e}^{k}\right)-Q=0 \\
& \frac{\partial}{\partial \tau}\left(\lambda T_{s}\right)+Q=0
\end{aligned}
$$

where $M=\rho, G=\beta \rho V, E=\rho e$, using the Beam and Warming $^{56}$ implicit time stepping approach. This code was written in curvilinear coordinates and seemed to perform well for low Reynolds number jets impinging the matrix. It was not developed further because of excessive computational time.

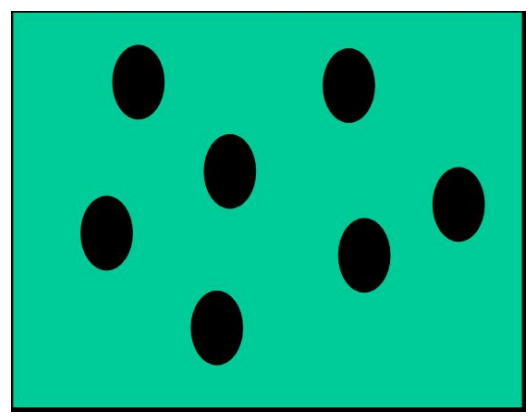

(a) Idealized Geomertry

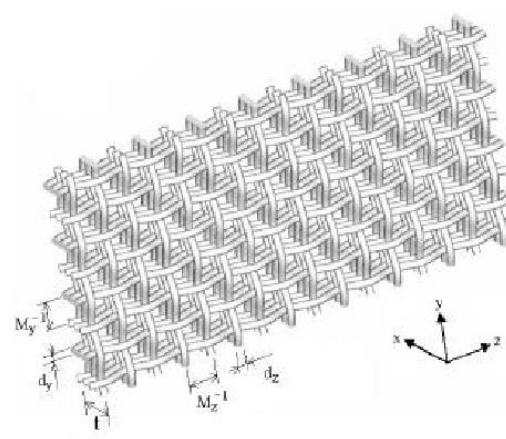

(b) Regularized Geometry

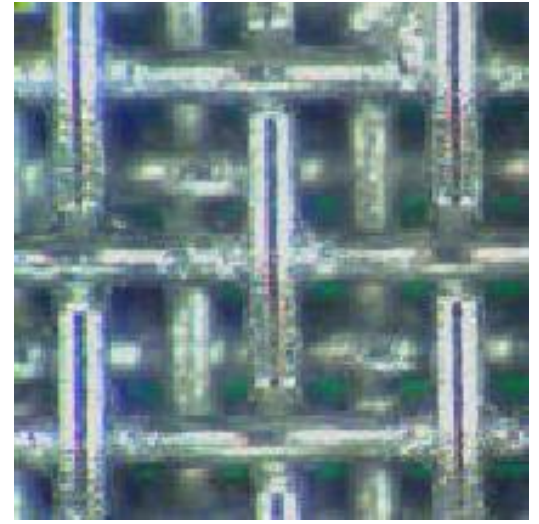

(c) Photographed Geometry

Figure 9. Regenerator Geometry

Another important issue is the geometrical shape of the matrix in the regenerator. As shown in Fig. 9, most regenerator models don't assume a precise geometrical shape for the elements of the regenerator. However, as reported in Park, ${ }^{49}$ a simple-to-fabricate woven mesh, consisting of bonded laminates of twodimensional plain-weave conductive screens can be manufactured to have a wide range of porosity and a highly anisotropic thermal conductivity vector. In addition to providing superior performance in many 
cases ${ }^{50}$ the regular geometry greatly simplifies the analysis. However, those mesh sheets are not woven wire screens formed by etching used in regenerators which may in practice not be as precisely formed as mesh sheets.

\section{Numerical Error and Efficiency}

The critical issues in simulating a Stirling engine are:

1. The artificial numerical losses should be a small percentage of the actual losses

2. The simulation must complete in a reasonable amount of time.

The first issue is a problem with many commercial codes that utilize low order methods. For example, this problem can be observed with a simple first order approximation of the first derivative:

$$
\frac{d F(t)}{d t} \approx \frac{\Delta F}{\Delta t}=\frac{F(t+\Delta t)-F(t)}{\Delta t}
$$

We may assume we are computing the derivative of a simple harmonic function, $F(t)=e^{i \omega t}$. We find the first order derivative approximation in Eq. (3) results in the solution:

$$
\begin{aligned}
\frac{\Delta F}{\Delta t}=\frac{e^{i \omega t}\left(e^{i \omega \Delta t}-1\right)}{\Delta t}= & i \omega e^{i \omega t}\left(\frac{e^{i \omega \frac{\Delta t}{2}}-e^{-i \omega \frac{\Delta t}{2}}}{2 i}\right)\left(\frac{e^{i \omega \frac{\Delta t}{2}}}{\omega \frac{\Delta t}{2}}\right) \\
& =i \omega e^{i \omega t}\left(\frac{\sin \left(\frac{\omega \Delta t}{2}\right)}{\frac{\omega \Delta t}{2}}\right) e^{i \omega \frac{\Delta t}{2}} \\
& =\frac{d F(t)}{d t} \underbrace{\left(\frac{\sin \left(\frac{\omega \Delta t}{2}\right)}{\frac{\omega \Delta t}{2}}\right)}_{\text {Dissipation }} \underbrace{e^{i \omega \frac{\Delta t}{2}}}_{\text {Dispersion }}
\end{aligned}
$$

Higher order approximations of the derivative introduce similar errors, but their relative effect is less.

\section{A. Time Advance Error}

In addition to the spatial and temporal discretizations which produce the dispersive and dissipative errors as discussed, another form of error which is important for oscillating flows is improperly modeled multidimensionsal boundary conditions.

As an example, consider the pressure near the displacer wall. The numerical approach can be expanded as a Taylor series in time:

$$
p(x, y, t+\Delta t)=p(x, y, t)+\Delta t \frac{\partial p}{\partial t}+\frac{\Delta t^{2}}{2 !} \frac{\partial^{2} p}{\partial t^{2}}+\ldots
$$

If the time derivatives are written as space derivatives (for simplicity consider 2D Euler flows):

$$
\frac{\partial p}{\partial t}=-\left(u \frac{\partial p}{\partial x}+v \frac{\partial p}{\partial y}+\gamma p\left(\frac{\partial u}{\partial x}+\frac{\partial v}{\partial y}\right)\right)
$$

Then clearly these spatial derivatives must be properly defined at a surface for the time derivative to be correct. Unfortunately, most commercial codes only impose the no-flow condition and these spatial derivative terms are not properly posed at the boundary. ${ }^{51}$ This error represents the wrong time-accurate physics near walls. If the walls are moving (such as in a displacer) this error is more pronounced. 
Higher time derivatives have many more terms in them that are generally incorrectly modeled at surfaces. For example in Fig. 10, the colored terms represent commonly improperly posed terms. The pink represents first order or dispersive error, the green represents diffusive error, and the blue represents an error in the entropy terms. In an oscillating flow loss study, these terms can become significant as time accumulates.

\section{B. Description of the SIMPLE method commonly used}

The Semi-Implicit Method for Pressure-Linked Equations (SIMPLE) is used in most of the commercial codes today. An understanding of its effect on Stirling simulations is important for interpreting the losses found from present computational analysis.

\section{Improving Efficiency}

One of the primary limitations of using commercial codes today for three-dimensional analysis of Stirling cycle engines is the time it takes for second order accurate analysis. A recent trend which improves this situation is relatively low-cost parallel computers (pictured in Fig. 11(a)). The trend is for more processors on a single board and for higher speed communications linking many boards together. Many commercial codes using the SIMPLE method can now utilize parallel computing, however, there still seems to be a practical limit due to the implicit nature of the method. Further improvement in performance can be expected by utilizing high order methods as shown in Fig. 11(b). The higher order methods in conjuction with parallel computing offer the promise of design speed analysis. An explicit method with these properties is presented in the next section.

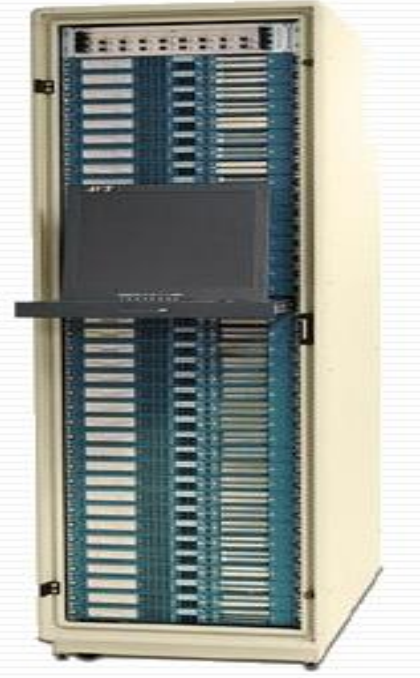

(a) Cluster Computing

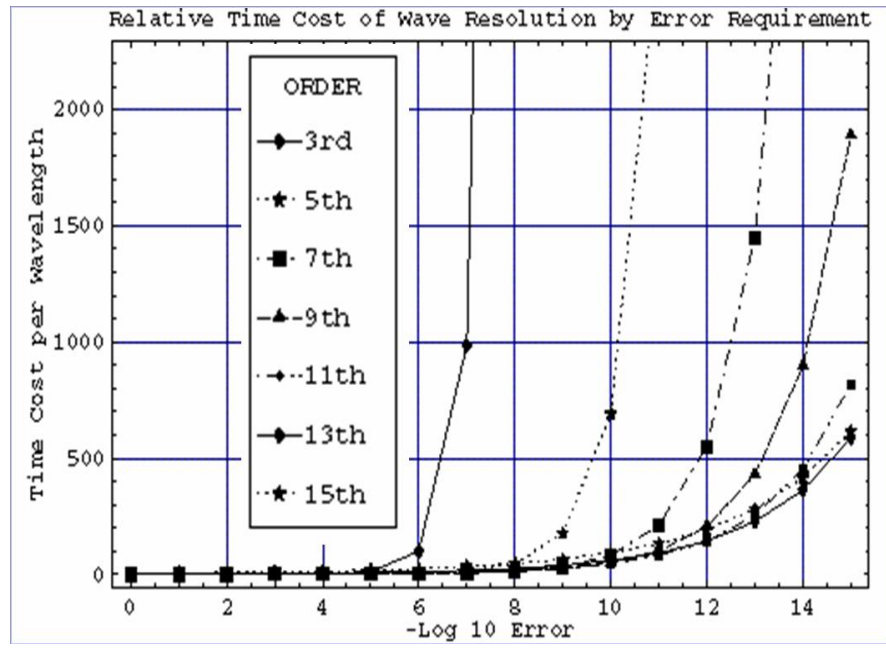

(b) Efficiency Chart

Figure 11. Enhancing Simulation Performance 


\section{Proposed Computational Stirling Analysis Numerical Approach}

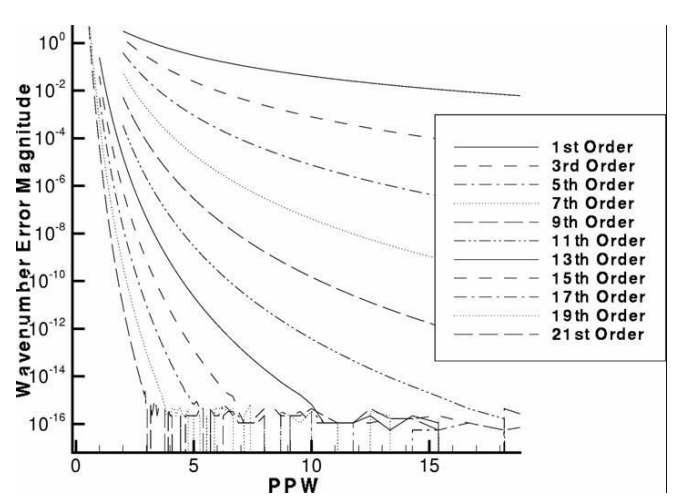

Figure 12. Points Per Wavelength Comparison

Computational Stirling Analysis (CSA) requires efficient, high-resolution simulation tools. Most current CSA techniques utilize low order finite-volume approaches because high order accuracy is considered too difficult or expensive to achieve and hopefully unnecessary for some problems. As shown in Fig. 12, these low order techniques require a relatively dense grid compared to the high order approaches. Two notable exceptions are the finite-volume WENO and finite element Discontinuos Galerkin Methods (DGM). ${ }^{57}$ However, they tend to be inefficient computationally due to their use of unstructured grids and complicated mathematics.

Although finite difference techniques have been developed which maintain low losses over time, they have great difficulty insuring flow conservation in crucial locations (i.e. appendix gap, moving geometry). Moreover, the finite difference form produces grid singularities at block corners of a multiblock curvilinear grid. In three dimensions, grid singularities become lines of only first order accuracy which swirling turbulent flow will force convected disturbances through.

It's accepted common practice to use low-order finite volume techniques in computational fluid dynamics ${ }^{58}$ precisely because of the drawbacks of finite-difference techniques in complex geometry. CSA has focused on low order finite-volume techniques because it is not currently clear how to extend finite-volume techniques to very high order. Only recently have modest improvements in the accuracy been achieved. For example, Agarwal ${ }^{59}$ has developed a fourth order finite volume technique for the Euler equations on unstructured grids. And, Wang ${ }^{60}$ developed a fourth order optimized structured/curvilinear finite-volume technique. And, Rezgui $^{61}$ has developed a third-order finite-volume Euler solver. A low dispersion finite volume technique by Nance ${ }^{62}$ used Tam's dispersion relationship preservation on the interpolated flux to improve spatial resolution. And most recently, Z.J. Wang ${ }^{63}$ developed a spectral volume method in which more degrees of freedom are made available by using subcells within a cell. As shown in Figs. 13 and 14, the third order method produced better results while using exactly the same number of degrees of freedom.

These recent developments demonstrate the feasibility and importance of high order low dissipation low dispersion finite-volume techniques. But their basic approaches severely limit their potential for very highorder extensions which are known to produce significant performance improvements ${ }^{51}$ without the need for special optimizations.

Building upon previously established Hermitian finite-difference approaches, ${ }^{51}$ this work utilizes the spatial derivatives of the convective fluxes to insure exceptionally high resolution and efficiency in complex geometries. The technique can be used to model a complete Stirling engine.

\section{Numerical Approach}

For pedagogical simplicity, the two-dimensional Euler equations will be shown, but the extension to fully viscous flows is straight-forward. The finite-volume form of the Euler equations is normally solved in physical 


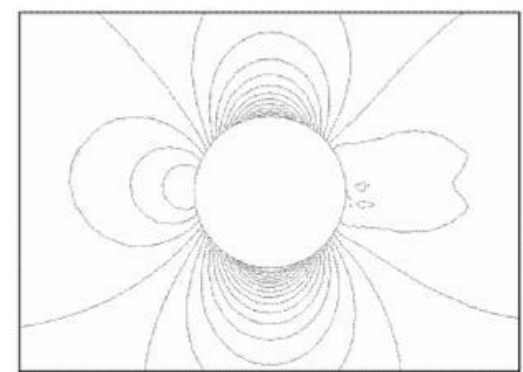

(a)

(a) 2nd Order Faceted

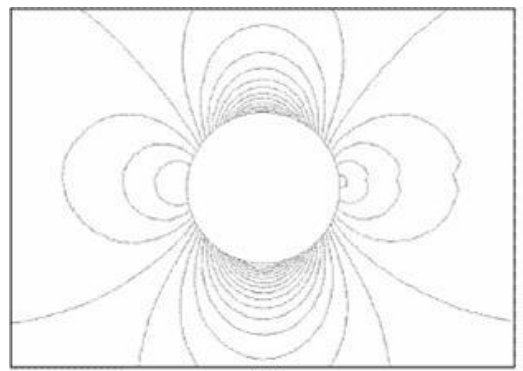

(b)

(b) 2nd Order Curved

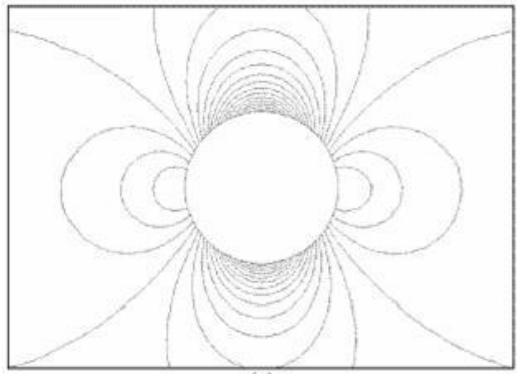

(c)

(c) 3rd Order

Figure 13. Density Contour-Comparing faceted geometry (a), curved geometry (b), and curved geomtry higher order (c)

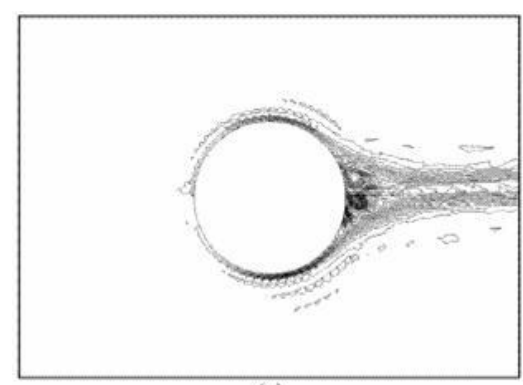

(a)

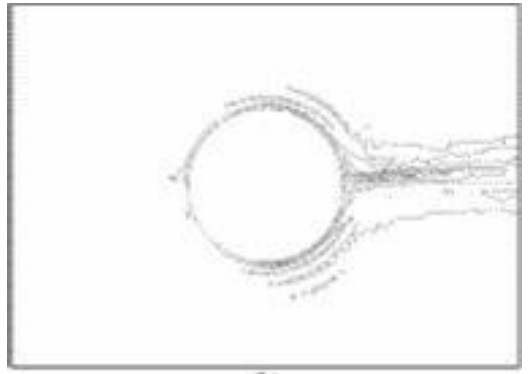

(b)

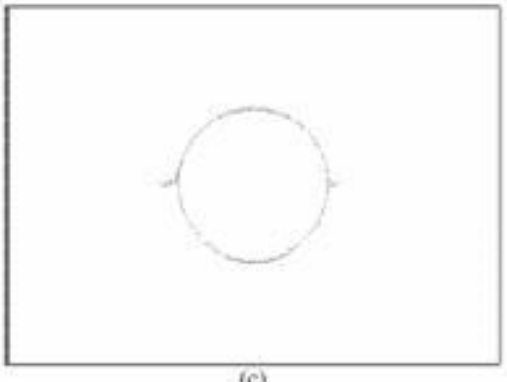

(c) 3rd Order

Figure 14. Entropy Production-Comparing faceted geometry (a), curved geometry (b), and curved geomtry higher order (c)

coordinates and can be written as: ${ }^{58}$

$$
\begin{gathered}
\vec{W}=\left[\begin{array}{c}
\rho \\
\rho u \\
\rho v \\
\rho E
\end{array}\right], \vec{F}_{c}=\left[\begin{array}{c}
\frac{\partial}{\partial t} \int_{\Omega} \vec{W} d \Omega+\oint_{\partial \Omega} \vec{F}_{c} d S=\int_{\Omega} \vec{Q} d \Omega \\
\rho u V+n_{x} p \\
\rho v V+n_{y} p \\
\rho H V
\end{array}\right], V \equiv \vec{v} \cdot \vec{n}=n_{x} u+n_{y} v \\
p=(\gamma-1) \rho\left[E-\frac{u^{2}+v^{2}}{2}\right], H=E+\frac{p}{\rho}
\end{gathered}
$$

However, recently structured multiblock grid generators have become available that can generate a very smooth curvilinear grid. Therefore, the following finite-volume form of the Euler equations can be used with many advantages over the traditional physical coordinate system finite volume (used in commercial packages) and the curvilinear multiblock finite difference methodologies. ${ }^{67,68}$

$$
\begin{aligned}
\int_{\Omega}\left(\frac{\partial \vec{W}_{1}}{\partial t}\right) d \xi d \eta & =-\int_{\Omega}\left(\frac{\partial \vec{F}_{1}}{\partial \xi}+\frac{\partial \vec{G}_{1}}{\partial \eta}\right) d \xi d \eta \\
& =-\oint_{\partial \Omega}\left(\vec{F}_{1} d \eta-\vec{G}_{1} d \xi\right)
\end{aligned}
$$


where

$$
\begin{aligned}
\vec{W}_{1} & =J \vec{W} \\
\vec{F}_{1} & =J \vec{F} \frac{\partial \xi}{\partial x}+J \vec{G} \frac{\partial \xi}{\partial y}=\vec{F} \frac{\partial y}{\partial \eta}-\vec{G} \frac{\partial x}{\partial \eta} \\
\vec{G}_{1} & =J \vec{F} \frac{\partial \eta}{\partial x}+J \vec{G} \frac{\partial \eta}{\partial y}=-\vec{F} \frac{\partial y}{\partial \xi}-\vec{G} \frac{\partial x}{\partial \xi}
\end{aligned}
$$

The jacobian determinant, $J$, is defined by:

$$
J \equiv \frac{\partial(x, y)}{\partial(\xi, \eta)} \equiv\left|\begin{array}{ll}
\frac{\partial x}{\partial \xi} & \frac{\partial y}{\partial \xi} \\
\frac{\partial x}{\partial \eta} & \frac{\partial y}{\partial \eta}
\end{array}\right|
$$

And the original Cartesian solution and flux vectors are:

$$
\vec{W}=\left\{\begin{array}{c}
\rho \\
\rho u \\
\rho v \\
\rho E
\end{array}\right\}, \vec{F}=\left\{\begin{array}{c}
\rho u \\
\rho u^{2}+p \\
\rho u v \\
\rho u E+p u
\end{array}\right\}, \vec{G}=\left\{\begin{array}{c}
\rho v \\
\rho u v \\
\rho v^{2}+p \\
\rho v E+p v
\end{array}\right\}
$$

$\mathrm{E}$ is total energy (internal energy plus kinetic energy) per unit mass, $E=e+\frac{V^{2}}{2}$.

The surface integrals can be simply performed in the computational space since all cells have unit spacing. Since derivatives of the solution are also available one can assume a polynomial shape function ${ }^{69}$ and the integrals become:

$$
\begin{aligned}
\int_{0}^{1} \vec{F}_{1}(\xi, \eta) d \eta & =\int\left(\vec{a}_{00}+\vec{a}_{10} \xi+\vec{a}_{01} \eta+\vec{a}_{11} \xi \eta\right) d \eta \\
& =\vec{a}_{00} \Delta \eta+\vec{a}_{10} \xi \Delta \eta+\vec{a}_{01} \frac{1}{2}(\Delta \eta)^{2}+\vec{a}_{11} \frac{1}{2} \xi(\Delta \eta)^{2} \\
\int_{0}^{1} \vec{G}_{1}(\xi, \eta) d \xi & =\int\left(\vec{a}_{00}+\vec{a}_{10} \xi+\vec{a}_{01} \eta+\vec{a}_{11} \xi \eta\right) d \xi \\
& =\vec{a}_{00} \Delta \xi+\vec{a}_{10} \frac{1}{2}(\Delta \xi)^{2}+\vec{a}_{01}(\Delta \xi) \eta+\vec{a}_{11} \frac{1}{2}(\Delta \xi)^{2} \eta
\end{aligned}
$$

where $\Delta \xi=\Delta \eta=1$. The $a_{i, j}$ coefficients can be found using Hermitian divided differences ${ }^{51}$ As was done by Agarwal $^{59}$ and similar to Goodrich ${ }^{70}$ the governing equations may be differentiated as follows in curvilinear coordinates:

$$
\int_{\Omega}\left(\frac{\partial^{m+n+1} \vec{W}_{1}}{\partial \xi^{m} \partial \eta^{n} \partial t}\right) d \xi d \eta=-\oint_{\partial \Omega}\left(\frac{\partial^{m+n} \vec{F}_{1}}{\partial \xi^{m} \eta^{n}} d \eta-\frac{\partial^{m+n} \vec{G}_{1}}{\partial \xi^{m} \eta^{n}} d \xi\right)
$$

The fluxes may be calculated either using Jameson ${ }^{71}$ style centered, but high order flux differences or by using a pseudo one-dimensional Riemann solution between the left and right states as follows: ${ }^{59}$

$$
\vec{F}_{1 m, n}=\frac{1}{2}[\underbrace{\vec{F}_{1 m, n}}_{\text {Right }}+\underbrace{\vec{F}_{1 m, n}}_{\text {Left }}-S|\Delta| \Delta^{-1} S^{-1}(\underbrace{\vec{F}_{1 m, n}}_{\text {Right }}-\underbrace{\vec{F}_{1 m, n}}_{\text {Left }})]
$$

where $\mathrm{S}$ is the similarity matrix for diagonilizing the Jacobian $\partial \vec{F}_{1 m, n} / \partial W_{m, n}, \Delta$ is the eigenvalue diagonal matrix, and $|\Delta|$ refers to the spectral radius of $\Delta$.

With these developments many arbitrary accuracy finite volume schemes can be implemented to arbitrary order accuracy in space. The time advancement may be implemented with Runge-Kutta schemes for low frequency Stirling simulations that contain high wavenumber requirements (steep flow gradients). Or the recursive time advance technique ${ }^{51}$ could be used to achieve arbitrary accuracy in time as well.

\section{Curvilinear Grid Issues}

One of the primary advantages of this finite-volume formulation over the common finite difference approach is in resolving grid singularity issues as shown in Fig. 15.

For the following reasons, a structured curvilinear multiblock arbitrary accuracy finite volume CSA code should be developed: 


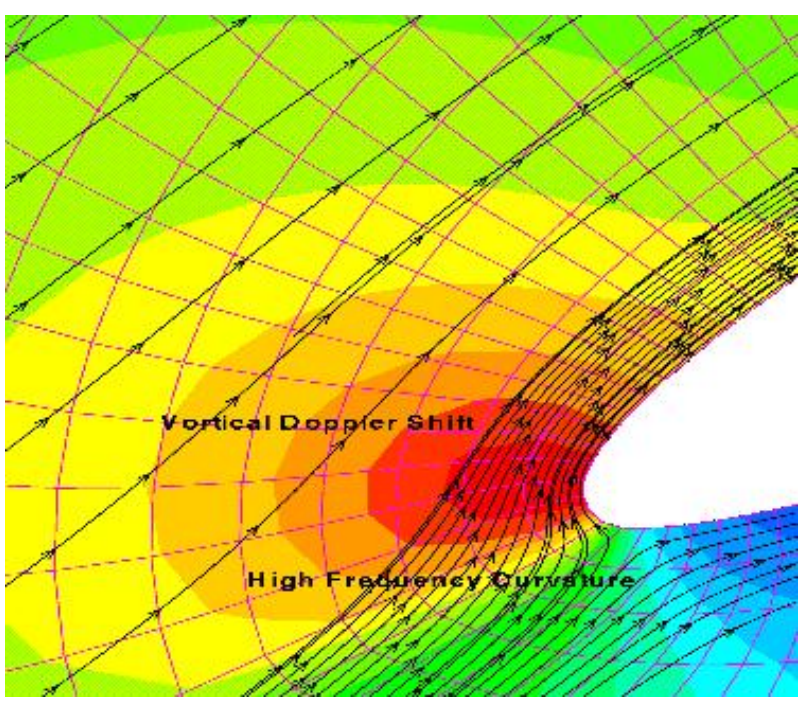

(a) Metric Term Gradient Distribution

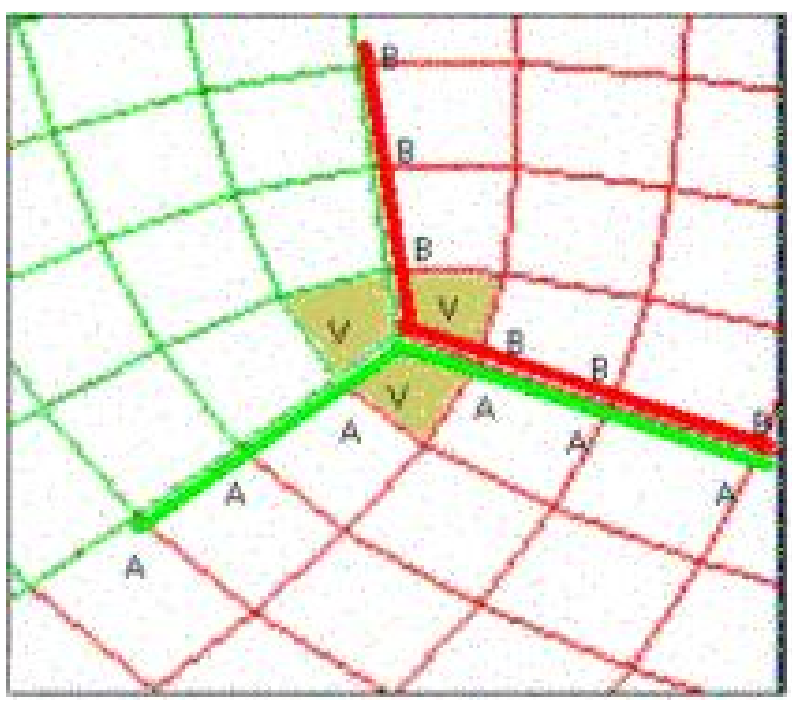

(b) Grid Singularity Avoided With Finite Volume

Figure 15. Grid singularities are unavoidable in complex geometries and act as a source of 1st order noise for finite difference methods. For example, calculating a derivative with a 7-point stencil (marked with "A" or "B") is indeterminate. A finite volume (with volumes "V") method communicates through faces and hence this grid poses no problems for it.

- Calculating spatial derivatives is reduced to $1^{\text {st }}$ order accuracy at grid singularities with a finitedifference method. However, a finite-volume method communicates through cell faces only and for the grid singularity shown all faces are uniquely defined.

- In three-dimensions this advantage is significant because grid singularities become lines of first order error. The swirling turbulent flow in the expansion and compression spaces will cause all convected disturbances to travel through this region with many undesirable side effects.

- In addition to enabling high accuracy everywhere this formulation will resolve high curvature without requiring as many grid points when the fluxes are written in strong conservation form.

- Parallel implementation is direct as well and does not require changing the wave propagation speeds that converting from an implicit compact to an explicit centered scheme does.

- Flat plates are easily solved and therefore code validation can be performed on standard oscillating flow flat plate heat exchanger before trying more complex problems.

\section{Time-Stepping Options}

One significant difference with time-stepping finite-volume cells relative to finite-difference and finiteelement cells is the time derivatives are actually cell averages. So it is possible to contain physical shocks within a cell and its cell average derivatives still are defined. Thanks to the property that integration ignores singularities, it seems plausible to have both high order accuracy and shocks without sacrificing either.

Standard Runge-Kutta time-stepping can be used, but it's not recommended because fidelity and stability is sacrificed since currently available methods effectively widen the stencil because they do not properly account for the presence of spatial derivative information on the grid. 


\section{A. Arbitrary Time Accuracy}

If higher operating frequencies in Stirling devices are encountered then a recursive ${ }^{51}$ technique of timestepping can be used on each cell. Again, since the mixed space-time derivatives are actually cell averages, they are still defined even in shocked flow.

\section{Flux Interpolation}

It is necessary to convert the spatially-averaged cell quantities to a form for interpolating the fluxes at the cell edges. The spatially averaged flow variables can be used as constraints as done by Lomax. ${ }^{72}$ This requires solving a matrix system for a polynomial that when volume integrated matches the spatially-averaged cell quantity. If Hermite data is on the grid, then for example, a single cell interpolation with $f, f_{x}, f_{x x}$ produces a fourth order technique if the left and right interpolated fluxes are averaged. However, by using data from two neighboring cells we can get $6^{\text {th }}$ order accuracy.

If we have up to $s$ derivatives in each cell, as shown in the figure 16,

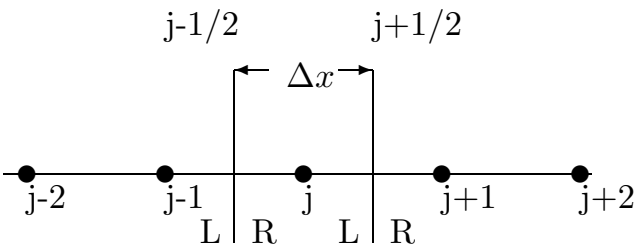

Figure 16. Control volume in one dimension

we can assume that the polynomial interpolating the flow variables looks like for cells $j$ and $j+1$ :

$$
u(\xi)=\sum_{i=0}^{2 s+1} a_{i} \xi^{i}
$$

The following constraints are applied to find the coefficients $a_{i}$ :

$$
\begin{gathered}
\frac{1}{\Delta x} \int_{-\Delta x / 2}^{\Delta x / 2} \frac{\partial^{m} u(\xi)}{\partial x^{m}} d \xi=\frac{\partial^{m} \bar{u}_{j}}{\partial x^{m}} \\
\frac{1}{\Delta x} \int_{\Delta x / 2}^{3 \Delta x / 2} \frac{\partial^{m} u(\xi)}{\partial x^{m}} d \xi=\frac{\partial^{m} u_{j+1}}{\partial x^{m}}
\end{gathered}
$$

with $\mathrm{m}=0$ up to $\mathrm{s}$.

The flux can then be calculated at the cell faces using the high order interpolant.

A $41^{\text {st }}$ order method using two cells would require inverting a $41 \times 41$ matrix which gets expensive. The problem is worse in multiple dimensions. Instead, we can use the extended divided differences ${ }^{51}$ and a process known as reconstruction via the primitive function ${ }^{64}$ or RP (see Colella and Woodward. ${ }^{73}$

Steps are for all $\mathrm{m}=0$ up to $\mathrm{s}$ :

Step 1 Find $F_{m}\left(x_{-1 / 2}\right)=0, F_{m}\left(x_{1 / 2}\right)=\Delta x \bar{f}_{m_{j}} F_{m}\left(x_{3 / 2}\right)=\Delta x \bar{f}_{m_{j}}+\Delta x \bar{f}_{j+1}$

Step 2 Use Hermitian divided differences on the data in Step 1 to create an interpolation polynomial. Choose a local coordinate system with $\xi=0$ somewhere in the two cells. The coefficients of $P(\xi)=b_{0}+b_{1} \xi+$ $\frac{1}{2} b_{2} \xi^{2}+\ldots$ can be found. This function is also easily differentiated. 
Step 3 And then, since the sample function $f(\xi)=\frac{\partial F}{\partial x}$ and $F(x) \approx P(x)$, a function approximating $\mathrm{f}(\mathrm{x})$ is $p(x)=\frac{d P(x)}{d x}$

For constant $\Delta x$ can use reconstruction via deconvolution.

With these developments high order finite volume integration is possible. The spatial accuracy is high via the previous step. Now we can time advance by converting higher order cell averaged time derivatives to first order cell averaged time derivatives using the Cauchy-Kowalewski approach.

So we time advance the averages (using the fluxes and their derivatives). We get new cell-averaged quantities at the next time level. We repeat the reconstruction to get new flux interpolants.

\section{Conclusion}

A review of the techniques used for analyzing the Stirling cycle has been presented. As the fidelity of this analysis has improved, so has the efficiency of the cycle in realized designs. Recent attempts at modeling a full Stirling engine have utilized commercial codes which have recently enhanced their ability to simulate moving, deforming, and sliding meshes. Further improvements in the analysis will require additional research in the key areas of regenerator modeling and higher fidelity numerical approaches.

The regenerator is perhaps at the same time the most difficult and important region to model. A combination of direct numerical simulation, better theoretical representations, and high efficiency numerical methods on parallel computers will be required. Some of the more recent higher fidelity simulations of porous media were presented and appeared to indicate a trend towards modeling with higher order methods.

Also, a review of the advantages of recently developed high fidelity finite volume methods was presented and a novel numerical approach for achieving extraordinary levels of fidelity in Stirling engine simulations was described. And, for completeness, the bibliography contains additional references that expand upon the review presented but due to the constraints of space and time have not been specifically commented on here. 


\section{References}

${ }^{1}$ Beale, W.T.:" Free Piston Stirling Engines - Some Model Tests and Simulations", [Preliminary investigation of free-piston Stirling engines.], SAE International Automtive Engineering Conference, Jan. 1969

2: Wood, J.G. : "Status of Free-Piston Stirling Technology at Sunpower, Inc.", 1st IECEC, AIAA 2003-6056, Aug. 2003

${ }^{3}$ Thieme, L.G.; Schreiber, J.G. : "NASA GRC Stirling Technology Development Overview", NASA/TM-2003-212454, Aug. 2003

${ }^{4}$ Oleson, S., Benson, S., Gefert, L., Patterson, M., Schreiber, J. : "Radioisotope Electric Propulsion for Fast Outer Planetary Orbiters", NASA/TM-2002-211893, Sept. 2002

${ }^{5}$ Cengel, Y.A.; Boles, M.A. : "Thermodynamics: An Engineering Approach", McGraw-Hill, 1989

${ }^{6}$ Tew, R.C., Thieme, L.G., Dudenhoefer, J.E. : "Recent Stirling Engine Loss-Understanding Results", 25th IECEC, NASA TM 103122, 1990

${ }^{7}$ Hirata, K., Kagawa, N., Takeuchi, M., Yamashita, I., Isshiki, N., Hamaguchi, K. : "Test Results of Applicative 100 W Stirling Engine", 96204.

${ }^{8}$ Ibrahim, M.B., Tew, R.C., Zhang, Z., Gedeon, D. Simon, T. : "CFD Modeling of Free-Piston Stirling Engines", NASA/TM-2001-211132, IECEC2001-CT-38, Sept. 2001.

${ }^{9}$ Dyson, R.W., "Technique For Very High Order Nonlinear Simulation and Validation", J. Comp. Acoustics, Vol. 10, No. 2, pp. 211-229, 2002.

${ }^{10}$ Carpenter, M.H., Nordstrom, J., Gottlieb, D. "A Stable andConservative Interface Treatment of Arbitrary Spatial Accuracy", Institute for Computer Applications in Science and Engineering (ICASE) Report No. 98-12, 1998.

${ }^{11}$ Carpeneter, M.H., Casper, J.H. "The Accuracy of Shock Capturing in Two Spatial Dimensions", AIAA 97-2107, July 1997.

${ }^{12}$ Tew, R.C., Ibrahim, M.B. : "Two-dimensional Compressible Non-Acoustic Modeling of Stirling Machine-Type Components", J. of Prop. and Power, Vol. 19, No. 5, Sept.-Oct. 2003

${ }^{13}$ Thieme, L.G., Schreiber, J.G., Mason, L.S. : "Stirling Technology Development at NASA GRC", NASA/TM-2001211315/REV1, Jan. 2002

${ }^{14}$ Tew, R.C., Cairelli, J.E., Ibrahim, M., Simon, T.W., Gedeon, D.: "Overview of NASA Multi-Dimensional Stirling Convertor Code Development and Validation Effort", NASA/TM-2002-211997, Dec. 2002.

${ }^{15}$ Tew, R., Ibrahim, M., Simon, T., Mantell, S., Gedeon, D., Qui, S., Wood, G.: "Overview 2003 of NASA Multi-D Stirling Convertor Code Development and DOE \& NASA Stirling Regenerator R \& D Efforts", NASA TM-2004-212908, Space Technology Applications Int. Forum 2004.

${ }^{16}$ Widmann, J.F. : Developed while author at Fluent training in Lebanon, N.H., 2004

${ }^{17}$ Schreiber, J. : "Tutorial on Free-Piston Stirling Power Conversion Technology (How Does it Work?), Space Technology and Applications International Forum, Feb. 2001

${ }^{18}$ Schreiber, J.G., Thieme, L.G., Mason, L.S.: "Status of Free-piston Stirling Power Conversion in the United States Space Program", 10th International Stirling Engine Conference, Osnabruk, Germany, Sept. 2001.

${ }^{19}$ Furlong, R., Shaltens, R. : "Technology Assessment of DOE's 55-We Stirling Technology Demonstrator Convertor (TDC)", NASA/TM-2000-210509, Oct. 2000

${ }^{20}$ Kaviany, M. : "Performance of a Heat Exchanger Based on Enhanced Heat Diffusion in Fluids by Oscillation: Analysis", J. of Heat Transfer, Vol. 112 (49), Feb. 1990

${ }^{21}$ Gedeon, D. : "Manifest: A Computer Program for 2-D Flow Modeling in Stirling Machines", NASA CR-182290, 1989

${ }^{22}$ Martini, W.R.: "Stirling Engine Design Manual, 2nd Ed.", NASA CR-168088, Jan. 1983

${ }^{23}$ West, C.D. : "Principles and Applications of Stirling Engines", Van Nostrand Reinhold Company, New York, 1986.

${ }^{24}$ Urieli, I., Berchowitz, D.M. : "Stirling Cycle Engine Analysis", Adam Hilger Ltd., Bristol, 1984.

${ }^{25}$ Schmidt, G. : "The Theory of Lehmann's Calorimetric Machine Z. Ver. Dtsch Ing.", Vol. 15, Part 1, 1871

${ }^{26}$ Berchowitz, D.M. : "Stirling Cycle Engine Design and Optimization", Aug. 1986

${ }^{27}$ Zimmerman, F.J. and Longsworth, R.C. : "Shuttle Heat Transfer", Cryogenic Engineering Conference paper H-5 Boulder, CO.

${ }^{28}$ Finkelstein, T. :"Computer Analysis of Stirling Engines", Proc. 10th IECEC, Aug. 1975.

${ }^{29}$ Urieli, I., Rallis, C.J., Berchowitz, D.O.M.: "Computer Simulation of Stirling Cycle Machines", Proc. 12th IECEC, Aug. 1977.

${ }^{30}$ Berchowitz, D.M. : "A Computer and Experimental Simulation of Stirling Cycle Machines", Master's Thesis, University of Witwatersrand, March 1978.

${ }^{31}$ Gedeon, D. : "GLIMPS Version 4: User's Manual", Gedeon Associates, July 1992.

32: Geng, S.M., Tew, R.C. : "Comparison of GLIMPS and HFAST Stirling Engine Code Predictions with Experimental Data", NASA TM-105549, 27th IECEC, Aug. 1992

${ }^{33}$ Gedeon, D. : "Sage - Object-oriented software for Stirling machine design", AIAA Paper 94-4106. 1994

${ }^{34}$ Gedeon, D. : "Sage:Stirling-Cycle Model-Class Reference Guide, Third Ed.", Gedeon Assocatiates, 1999

${ }^{35}$ Gedeon, D. : "Sage:User's Guide, Third Edition" Gedeon Assocatiates, 1999 
1993.

${ }^{36}$ Huang, S.C. : "HFAST Version 2.00: User Manual", Mechanical Technology, Inc., NASA Contract NAS3-25330, Jan.

${ }^{37}$ Martini, W.R. : "A Computer Simulation of the Transient Response of a 4 Cylinder Stirling Engine with Burner and Air Preheater in a Vehicle", Martini Engineering, DOE/NASA/0226-1, NASA CR-165262, March 1981

${ }^{38}$ Renfroe, D.A. : "A Computer Model of a Stirling Engine Using a Two-Phase Two-Component Working Fluid", Ph.D. Dissertation, Texas A\&M University, May, 1981.

39: Regan, T.F., Gerber, S.S., Roth, M.E. : "Development of a Dynamic, End-to-End Free Piston Stirling Convertor Model", NASA/TM-2004-212941

${ }^{40}$ Peric, M., Scheuerer, G.: "CAST - A Finite Volume Method for Predicting Two-dimensional Flow and Heat Transfer Phenomena", GRS-Technische Notiz, SSR-89-01, Sept. 1989.

${ }^{41}$ Patankar, S.V., Spalding, D.B. : "A Calculation Procedure for Heat, Mass, and Momentum Transfer in ThreeDimensional Parabolic Flows", Int. J. Heat Mass Transfer, Vol. 15, p. 1787, 1972

${ }^{42}$ Ibrahim, M., Kannapareddy, M. : "Computational Heat Transfer Analysis for Oscillatory Channel Flows", NASA-CR199238,1992

${ }^{43}$ Guo, G., Kurzweg, U.H. : "2D Numerical Simulation of Heat Transfer in a Stirling Microrefrigerator Model", AIAA

Paper 96-1807, 31st AIAA Thermophysics Conference, New Orleans, LA, June, 1996

${ }^{44}$ Ibrahim, M., Mittal, M.: To be presented at AIAA IECEC conference, Rhode Island, 2004.

${ }^{45}$ Wilson, S.D., Dyson, R.W., Tew, R.C. : "Multi-D CFD Modeling of Free-Piston Stirling Convertor at NASA GRC", 2nd AIAA IECEC, Aug. 2004.

${ }^{46}$ Star CD, "Methology",Computational Dynamics Limited, 2002 http://www.fnb.maschinenbau.tudarmstadt.de/de/software/starcd/manuals/method/star_method.pdf

${ }^{47}$ Zhang, Z. Posted on the web at http://www.cfdreview.com/jobs.pl?op=view_res\&rid=264, No specific details since proprietary, 2003

${ }^{48}$ Computational Fluids Dynamics Company website at http://www-waterloo.ansys.com/cfx.

${ }^{49}$ Park, J., Ruch, D., and Wirtz, R.A. : "Thermal/Fluid Characteristics of Isotropic Plain-weave Screen Laminates as Heat Exchange Surfaces", AIAA 2002-0208, 2002.

${ }^{50}$ Kitahama, D., Takizawa, H., Kagawa, N., Matsuguchi, A., Tsuruno, S.L: "Performance of New Mesh Sheet for Stirling Engine Regenerator", 1st IECEC, Portsmouth, VA, Aug. 2003

${ }^{51}$ Dyson, R.W. : "Towards Arbitrary Accuracy Inviscid Surface Boundary Conditions", AIAA Paper 2002-2438, June 2002

${ }^{52}$ Makhkamov, K., Ingham, D.B. : "Theoretical Investigations on the Stirling Engine Working Process", A00-37715, AIAA-2000-2815, 2000

${ }^{53}$ Makhkamov, K., Djumanov, D. : "Three-dimensional CFD modeling of a Stirling engine”, ST_TA1_15, 11th Int. Stirling Engine Conf., Rome, Italy, Nov. 2003

${ }^{54}$ Mahkamov, K., Djumanov, D., Orunov, B., Korobkov, A. : "A $\gamma$ - Type Stirling Engine: Some Results of Second-Order Numerical Simulations and Experimentals Tests", 1st Int. Energy Conversion Eng. Conf., AIAA 2003-5933, Aug. 2003

${ }^{55}$ Gedeon, D., Tew, R. : Personal Communication, 2004

${ }^{56}$ Beam, R.M., Warming, R.F. : "An Implicit Finite-Difference Algorithm For Hyperbolic Systems in Conservation Law Form", J. Comp. Phys., Vol. 22, No. 1, pp. 87-110, 1976

${ }^{57} \mathrm{Shu}$, C., "High-order Finite Difference and Finite Volume WENO Schemes and Discontinuous Galerkin Methods for CFD", Int. Journal of Comp. FluidDynamics, Vol. 17, No. 2, pp. 107-118, 2003

${ }^{58}$ Blazek, J., "Computational Fluid Dynamics: Principles and Applications", Elsevier, New York, 2001

${ }^{59}$ Agarwal, R.K. and Halt, D.W., "A Compact High-Order Unstructured Grids Method for the Solution of Euler equations", Int. Journal For Numerical Methods in Fluids, Vol. 31, pp. 121-147, 1999

${ }^{60}$ Wang, G. and Sankar, L.N., "Prediction of Rotorcraft Noise with aLow-Dispersion Finite Volume Scheme", Vol. 38, No. 3, March 2000

${ }^{61}$ Rezgui, A., Cinnella, P., Lerat, A., "Third-order Accurate Finite Volume Schemes for Euler Computations on curvilinear meshes", Computers \& Fluids, Vol. 30, pp. 875-901, 2001

${ }^{62}$ Nance, D.V., Viswanathan, K., Sankar, L.N., "Low-Dispersion Finite Volume Scheme for Aeroacoustic Applications", AIAA J., Vol. 35, No. 2, Feb. 1997

${ }^{63}$ Wang, Z.J. : "The spectral-volume method for the Euler equations with high-order boundary representations", Computational Fluid and Solid Mechanics, K.J. Bathe (Editor), 2003

${ }^{64}$ Laney, C. B., "Computational Gasdynamics", Cambridge University Press, New York, 1998

${ }^{65}$ Stanescu, D., Habashi, W.G., "2N-Storage Low Dissipation and Dispersion Runge-Kutta Schemes for Computational Acoustics", Journal of Computational Physics, Vol 143, no. 2, 1998, pp. 674.

${ }^{66}$ Ralston, A., Rabinowitz, P., "A First Course in Numerical Analysis", McGraw-Hill Book Company, New York, 1978.

${ }^{67}$ Anderson, J.D., "Computational Fluid Dynamics: the Basics with Applications", McGraw-Hill, 1995

${ }^{68}$ Hoffman, K.A., Chiang, S.T., "Computational Fluid Dynamics ForEngineers - Volume II", Engineering Education System, Wichita, Kansas, 1993 
${ }^{69}$ Ferziger, J.H., Peric, M., "Computational Methods for Fluid Dynamics", Springer-Verlag, 1999

${ }^{70}$ Goodrich, J.W., "Accurate finite difference algorithms for computational aeroacoustics, " in Computational Fluid Dynamics Review 1998, ed. M.M. Hafez and K. Oshima (World Scientific, Singapore, 1998).

${ }^{71}$ Jameson, A.; Schmidt, W.; Turkel, E.: "Numerical Solutions of the Euler Equations by Finite Volume Methods Using Runge-Kutta Time-Stepping Schemes. AIAA Paper 81-1259, 1981.

${ }^{72}$ H. Lomax, T.H. Pulliam, D.W. Zingg, "Fundamentals of Computational Fluid Dynamics", Springer-Verlag, 2001

${ }^{73}$ Collela, P., and Woodward, P.R. 1984. "The Piecewise Parabolic Method (PPM) for Gas-Dynamical Simulations", Journal of Comp. Physics, 54: 174-201.

${ }^{74}$ Daniele, C.J., Lorenzo, C.F. A Four-Cylinder Stirling Engine Computer Program with Dynamic Energy Equation, NASA-TM-83053, May, 1983

${ }^{75}$ Lorenzo, C.F. and Daniele, C.J. A Four-Cylinder Stirling Engine Controls Model, NASA-TM-81648, Automotive Technol. Develop. Contractor Coordination Meeting, Dearborn, MI, Nov. 1980

${ }^{76}$ Daniele, C.J., Lorenzo, C.F. Preliminary results from a Four-Working Space, Double-Acting Piston, Stirling Engine Controls Model NASA-TM-81569, Intersoc. Energy Conversion Eng. Conf., Aug. 1980

${ }^{77}$ Daniele, C.J., Lorenzo, C.F. Energy-state Formulation of Lumped Volume Dynamic Equations with Application to a Simplified Free Piston Stirling Engine International Conference on Energy and the Environment, Pittsburgh, PA, May 1979

${ }^{78}$ Chen, N.C.J., and Griffin, F.P. A Review of Stirling Engine Mathematical Models, ORNL/CON-135, August, 1983.

${ }^{79}$ Weisend, J.G. : "Handbook of Cryogenic Engineering", Taylor \& Francis, 1998

${ }^{80}$ Muskat, M. : "The Flow of Homogeneous Fluids Through Porous MEdia", McGraw-Hill, 1937

${ }^{81}$ Spanos, T.J.T. : "The Thermophysics of Porous Media", Chapman \& Hall/CRC, 2002

${ }^{82}$ Cortis, A. : "Dynamic Acoustic Parameters of Porous Media; a theoretical, Numerical, and Experimental Investigation", Delft University Press, 2002.

${ }^{83}$ Ingham, D.B. : "Transport Phenomena in Porous Media II", Pergamon, 2002.

${ }^{84}$ Organ, A.J. : "The Regenerator and the Stirling Engine", Mechanical Engineering Publications Limited, 1997.

${ }^{85}$ Rizzo, J.G. : "Modelling Stirling and Hot Air Engines", Patrick Stephens, Wellingborough, 1985.

${ }^{86}$ Dragutinovic, G.D. and Baclic, B.S.: "Operation of Counterflow Regenerators", Volume 4, Computational Mechanics Publications, Boston, 1998

${ }^{87}$ D. Y. Goswami, Kreith, F., Kreider, J.F. : "Principles of Solar Engineering, 2nd Ed.", Taylor \& Francis, 2000

${ }^{88}$ Bauwens, L. : "Numerical Modeling of Stirling Crycoolers", AIAA 94-0130, 32nd Aerospace Sciences Meeting \& Exhibit, Jan., 1994.

${ }^{89}$ Hargreaves, C.M. : "The Philips Stirling Engine", Elsevier, New York, 1991.

${ }^{90}$ Organ, A.J. : "Thermodynamics and Gas Dynamics of the Stirling Cycle Machine", Cambridge University Press, 1992

${ }^{91}$ Bastian, P. : "Higher Order Discontinuous Galerkin Methods for Flow and Transport in Porous Media", 2003

${ }^{92}$ Simon, T.W. and J.R. Seume : "A Survey of Oscillating Flow in Stirling Engine Heat Exchangers", NASA-CR-182108, Mar. 1988.

${ }^{93}$ Gedeon, D. : "Computational Techniques for the two-dimensional Gasdynamic Equations in Stirling Engine Regenerators and Associated Manifolds", 1985.

${ }^{94}$ Niu, Y., Ibrahim, M., Tew, R., Gedeon, D. : "Measurements of Unsteady Convective Heat Transfer Rates Within a Stirling Regenerator Matrix Subjected to Oscillatory Flow", AIAA, 2003

${ }^{95}$ Niu, Y., Ibrahim, M., Tew, R., Gedeon, D. : "Jet Penetration into a Stirling Engine Regenerator Matrix with Various Regenerator-to-Cooler Spacings", AIAA, 2003

${ }^{96}$ Adolfson, D.A., Simon, T.W., Ibrahim, M.B., Gedeon, D.: "Unsteady Fluid Dynamics Simulation of a Stirling Engine Heater Head", AIAA, 1st Int. Energy Conversion Engineering Conference, Aug. 2003

${ }^{97}$ Bartolotta, P.A., Bowman, R.R., Krause, D.L., and Halford, G.R. : "Long-term Durability Analysis of a 100,000+ HR Stirling Power Convertor Heater Head", AIAA, A00-37736, 2000

${ }^{98}$ Yuan, S.W.K. and Spradley, I.E. : "A Third Order Computer Model for Stirling Refrigerators", Advanced in Cryogenic Engineering, Vol. 37, Part B, Plenum Press, New York, 1992

${ }^{99}$ Chung T.J.: "Computational Fluid Dynamics", Cambridge University Press, 2003

${ }^{100}$ Daniele, C.J., Lorenzo, C.F. : "Preliminary Results from a Four-Working Space, Double-Acting Piston, Stirling Engine Controls Model", 15th IECEC, Aug., 1980.

${ }^{101}$ Taylor, D.R. : "The method of characteristics applied to Stirling engines", 19th IECEC, Aug. 1984

${ }^{102}$ Simon, T.W., Niu, Y., Sun, L. : "Some Comments on Dynamic Similitude as Applied to Our Physical Simulations of Stirling Engines", Memorandum, Sept. 2003.

${ }^{103}$ Bauwens, L. : "Pressure Gradients in Stirling Engines", AIAA Paper 94-3956, 29th IECEC, 1994.

${ }^{104}$ Gogineni, S.P., Joslin, R.D., Gaitonde, D.V. : "Fluid Dynamics", Aerospace America, Dec. 2003.

${ }^{105}$ Guidry, D.J., Parker, J.T., McCandless, A.B., Motakef, S., Kelly, K.W. : "X-Ray Lithography Fabricated Microchannel Regenerators for Cryocoolers", International Mezzo Technologies Report.

106: Tomlinson, B.J. : "Parametric Cryocooler Performance Prediction Modeling", AIAA 99-4626, Sept. 1999 
107: Qui, S., Peterson, A.A. : "Linear Dynamic Modeling and Numerical Simulation of an STC Stirling Convertor", 1st Int. Energy Conv. Eng. Conf., Aug. 2003

108: Regan, T. : "Free-Piston Stirling Convertor Controller Development at NASA Glenn Research Center", 1st IECEC, AIAA Paper 2003-5931, Aug. 2003

109: Guo, G., Kurzweg, U.H. : "2D numerical simulation of heat transfer in a Stirling microrefrigerator model", AIAA, Thermophysics Conference, June, 1996.

${ }^{110}$ Ibrahim, M.B., Tew, R.C., Dudenhoefer, J.E. : "Two-Dimensional Numerical Simulation of a Stirling Engine Heat Exchanger", NASA TM-102057, 24th IECEC, Aug. 1989.

${ }^{111}$ Allen, D.J., Cairelli, J.E. : "Test Results of a 40-kW Stirling Engine and Comparison with the NASA Lewis Computer Code Predictions", NASA TM-87050, 20th IECEC, Aug. 1985.

${ }^{112}$ Oseid, K.L. : "Numerical Prediction of Turbulent Oscillating Flow and Heat Transfer in Pipes with Various End Geometries", NASA CR 198416, Oct. 1995

${ }^{113}$ Koehler, W.J., Patankar, S.V., Ibele, W.E. : "Numerical Prediction of Turbulent Oscillating Flow and Associated Heat Transfer", NASA CR 187177, Aug. 1991.

${ }^{114}$ Morgan, P.E., Visbal, M.R., Sadayappan, P. : "Development and Application of a Parallel Implicit Solver for Unsteady Viscous Flows", Int. J. of Comp. Fluid. Dyn., 2002, Vol. 16(1), pp. 21-36

${ }^{115}$ Yonglin, J., Jiang, Y., Zhou, Y. : "Experimental study of the oscillating flow Characteristics for a Regenerator in a Pulse Tube Cryocooler", Elsevier, Cryogenics, Vol. 38, pp. 649-656, 1998

${ }^{116}$ Gedeon, D. : "Numerical advection errors in Stirling cycle nodal analyses", IECEC, Aug. 1984.

${ }^{117}$ Walker, G., Senft, J.R. : "Free Piston Stirling Engines", Stirling Machine World, Springer-Verlag, 1985. 


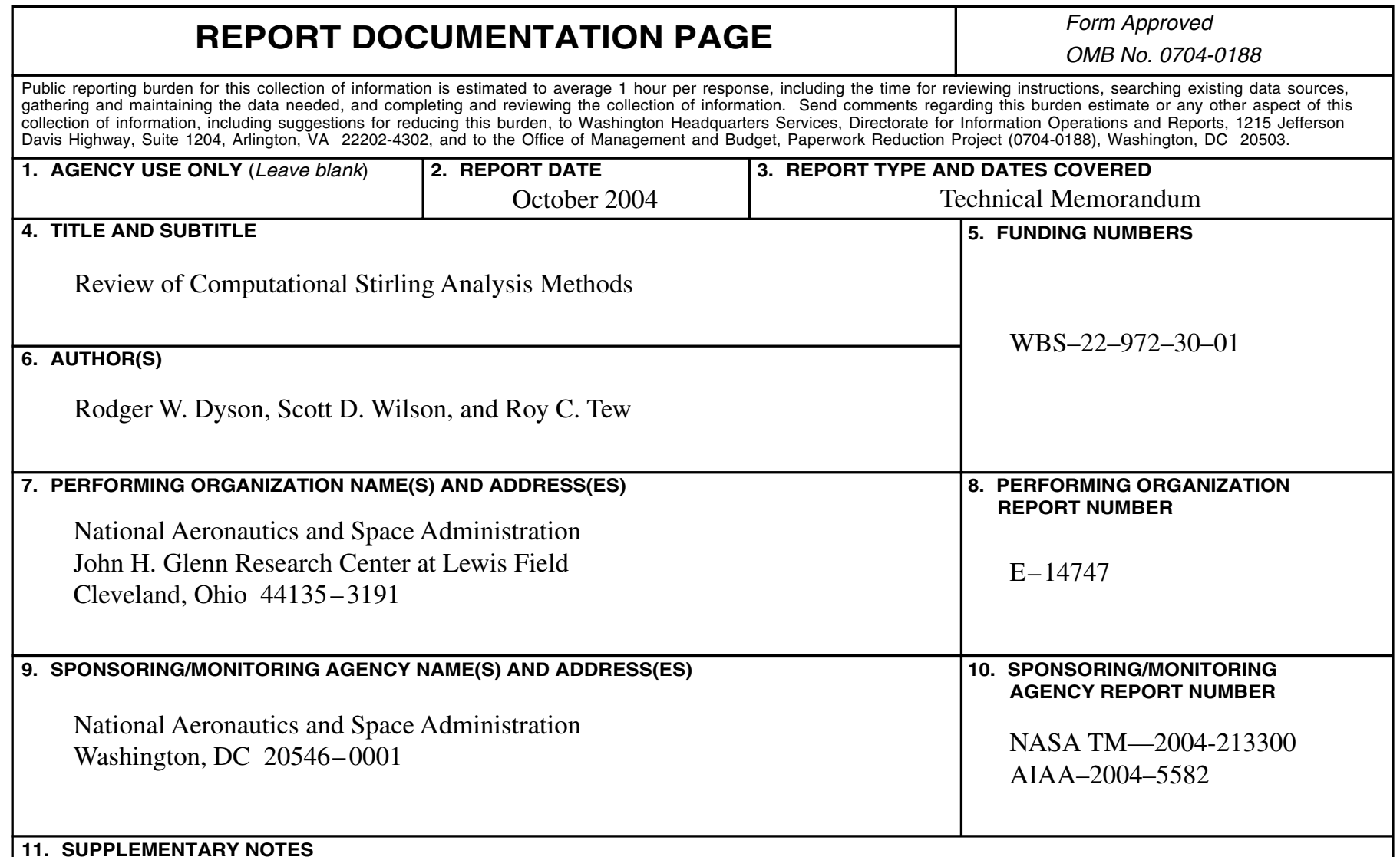

\section{SUPPLEMENTARY NOTES}

Prepared for the Second International Energy Conversion Engineering Conference sponsored by the American Institute of Aeronautics and Astronautics, Providence, Rhode Island, August 16-19, 2004. Rodger W. Dyson and Roy C. Tew, NASA Glenn Research Center; Scott D. Wilson, Sest, Inc., 18000 Jefferson Park, Suite 104, Middleburg Heights, Ohio 44130. Responsible person, Rodger W. Dyson, organization code 5490, 216-433-9083.

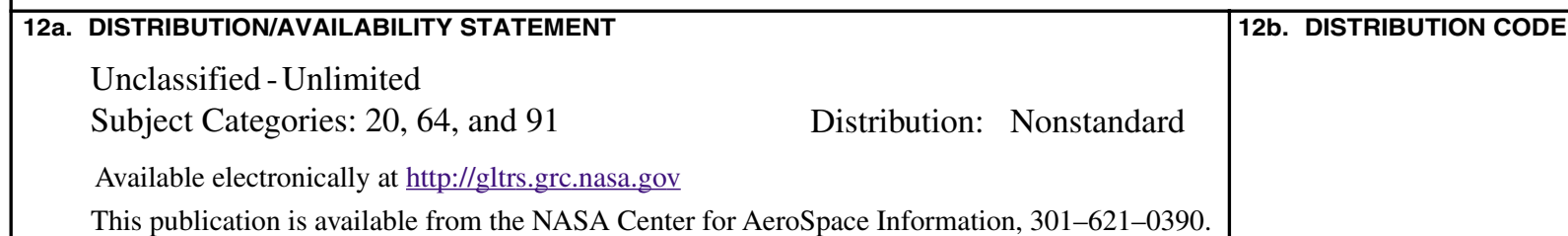

\section{ABSTRACT (Maximum 200 words)}

Nuclear thermal to electric power conversion carries the promise of longer duration missions and higher scientific data transmission rates back to Earth for both Mars rovers and deep space missions. A free-piston Stirling convertor is a candidate technology that is considered an efficient and reliable power conversion device for such purposes. While already very efficient, it is believed that better Stirling engines can be developed if the losses inherent its current designs could be better understood. However, they are difficult to instrument and so efforts are underway to simulate a complete Stirling engine numerically. This has only recently been attempted and a review of the methods leading up to and including such computational analysis is presented. And finally it is proposed that the quality and depth of Stirling loss understanding may be improved by utilizing the higher fidelity and efficiency of recently developed numerical methods. One such method, the Ultra HI-Fl technique is presented in detail.

\begin{tabular}{|c|c|c|}
\hline \multicolumn{3}{|c|}{$\begin{array}{l}\text { 14. SUBJECT TERMS } \\
\text { High resolution; Efficient radioisotope; Prometheus }\end{array}$} \\
\hline $\begin{array}{l}\text { 17. SECURITY CLASSIFICATION } \\
\text { OF REPORT } \\
\text { Unclassified }\end{array}$ & $\begin{array}{l}\text { 18. SECURITY CLASSIFICATION } \\
\text { OF THIS PAGE } \\
\text { Unclassified }\end{array}$ & $\begin{array}{l}\text { 19. SECURITY CLASSIFICATION } \\
\text { OF ABSTRACT } \\
\text { Unclassified }\end{array}$ \\
\hline
\end{tabular}



